\title{
Conjunctival Involvement in a Patient with Cutaneous Malignant Melanoma
}

Malignant Melanoma (MM) is the most serious skin tumor and its incidence is doubling every 10 years. MM has been classified into subtypes which include melanoma in situ, lentigo maligna melanoma, nodular melanoma, acral lentiginous melanoma, desmoplastic melanoma, superficial spreading melanoma. Although the subtypes of MM overlap, there are characteristic clinical features of each that are generally recognizable. Evaluation of pigmented lesions requires correlation of clinical findings with risk factors, family history, and histology. A representative skin biopsy should be performed on any lesion suspected of being MM, even if the possibility is remote. The earliest metastases are often in regional lymph nodes. Surgical lymphadenectomy usually can control regional disease. Liver, lung, bone, and brain are common sites of metastases $[1,2]$. Conjunctival metastases from a cutaneous melanoma are a rare and ominous sign of widely disseminated disease [3-5]. Once widespread metastatic disease is established, the likelihood of cure is low. Herein, we report a rare case of MM recurred in the conjunctiva.

In the summer of 1997 a 31-year-old woman noticed widening of a mole on the posterior of left arm over 6 months. She was a swimmer and scuba diver. She stated that she had a lot of moles since childhood. The nevus was operated with a wide excision and a $2 \mathrm{~cm}$ margin. The pathological examination revealed that it was a superficially spreading MM $1.2 \mathrm{~mm}$ deep. Lymph node dissection and scans showed no metastatic disease. The patient was diagnosed with localized disease of stage IB.

\begin{tabular}{ll}
\hline KARGER & ( ) 2002 S. Karger GmbH, Freiburg \\
$\begin{array}{l}\text { Fax +497614520714 } \\
\begin{array}{l}\text { E-mail Information@Karger.de } \\
\text { www.karger.com }\end{array}\end{array}$ & Accessible online at: \\
www.karger.com/journals/onk
\end{tabular}


In spring of 1999, physical examination showed a hypermelanotic lesion in her left eye. The lesion on the conjunctiva was excised and cryotherapy was carried out. The pathological examination revealed that it was a conjunctival melanoma $1 \mathrm{~mm}$ deep. The surgical borders were intact. Scans showed no other metastatic lesion.

Cutaneous MM is a treacherous disease carrying high mortality rates. Only when diagnosed early, it is completely curable. Our case presented at an early stage, but after 2 years conjunctival involvement was observed. Conjunctival MM was the first sign of tumor dissemination. We want to share our experience with our colleagues that conjunctival recurrence is a rare and poor prognostic sign of MM.

$$
\text { L. Filik }{ }^{a} \text {, T. Oskay }{ }^{a} \text {, O. Ozyilkan }{ }^{b}
$$

${ }^{a}$ Bayindir Tip Merkezi-Medical Centre, Sogutozu, Ankara,

Turkey

${ }^{b}$ Baskent University, Division of Oncology, Ankara, Turkey

\section{References}

1 Champeu F, Verola O: Malignant Melanoma. Ann Chir Plast Esthet 1998:43: $411-420$

2 Porras BH, Cockerell CJ: Cutaneous malignant melanoma: Classification and clinical diagnosis. Semin Cutan Med Surg 1997;16:88-96.

3 Shields CL: Conjunctival melanoma: Risk factors for recurrence, exenteration, metastasis, and death in 150 consecutive patients. Trans Am Ophtalmol Soc 2000;98:471-492.

4 Kwapiszeski BR, Savitt ML: Conjunctival metastasis from a cutaneous melanoma as the initial sign of dissemination. Am J Ophtalmol 1997;123:266-268.

5 Kiratli H, Shields CL, Shields JA, DePotter P: Metastatic tumours to the conjunctiva: Report of 10 cases. Br J Ophtalmol 1996;80:5-8.

For correspondence (both letters)

Levent Filik M.D.

Cemal Gursel Caddesi-Street No. $52 / 2$

Kurtulus, Ankara (Turkey)

Tel. +90 5324352596

E-mail leventfilik@yahoo.co.uk 